\title{
Pathways to Technology Leadership
}

\section{Dr. Andrew C Hurt, Purdue University, West Lafayette}

Dr. Hurt is an Assistant Professor in the Department of Technology Leadership and Innovation at Purdue University in West Lafayette, IN. His expertise is in the area of Human Resource Development, with particular emphasis on training and development, technology leadership, and organizational development practices within organizations.

\section{Mr. Robert C Deadman, Ivy Tech Community College \\ Dr. Jenny Daugherty, Purdue University, West Lafayette \\ Mr. Daniel O Lybrook, Purdue University, West Lafayette}

Daniel Lybrook is an Associate Professor in the Department of Technology Leadership and Innovation in the College of Technology at Purdue University.He has expertise in Human Resource Development and Curriculum Development. 


\title{
Pathways to Technology Leadership
}

\begin{abstract}
Technology-rich organizations need people who can pair technical knowledge, skills, and abilities with an ability to lead people. Organizations have historically focused on hiring employees with either a strong technical competence or a strong leadership competence. The $21^{\text {st }}$ century technology leader needs both. A gap exists between what organizations need from employees in the way of technical competence and leadership capability and what educational institutions provide. Therefore, educational institutions need to adjust their curriculum to meet this need. This paper describes efforts to move the field of science and technology forward by outlining a plan to uncover the competencies associated with technology leadership and propose a way of integrating these competencies into technical education programs. The proposed program will ensure that students have both technical skills and the ability to lead. This is a planned effort of two institutions of higher education (a community college and a research intensive university) to develop a collaborative educational pathway for the technology leaders of tomorrow.
\end{abstract}

\section{Introduction}

Over the last few years, there have been several reports documenting the need for improving STEM education and advancing a national innovation strategy. In 2009, the National Economic Council published a report entitled A Strategy for American Innovation: Driving Towards Sustainable Growth and Quality Report that outlined three broad-based strategies: (a) investment in the building blocks of American innovation; (b) promotion of competitive markets that spur productive entrepreneurship; and (c) catalyzing breakthroughs for national priorities. One of the building blocks specified in the report is educating the next generation with 21 st century knowledge and skills while creating a world-class workforce.

In another report from the National Academies, Rising to the Challenge: U.S. Innovation Policy for Global Economy, the authors pointed out that the U.S. is still a world leader in innovation capacity however there is concern that we are not translating this capacity into economic growth and employment. The authors of the report further added: "the United States is not paying sufficient attention to the essential pillars of the innovation ecosystem that have helped make the U.S." ${ }^{21}$ This includes America's research universities, the high-tech manufacturing base, and its physical infrastructure. They pointed to the United States ranking of "total competitiveness" from the World Economic Forum slipping from No. 1 to No. 5. In addition, the U.S. ranked 13th in "higher education and training," 16th in "infrastructure," and 20th in "technological readiness." 15

Indiana, specifically, ranks low in terms of adults with a college degree - 42nd out of 50 states in adults with a Bachelor's degree and 29th in adults with an Associate's degree. ${ }^{18}$ This lack of training is of paramount concern for Indiana companies. In a 2012 survey of Indiana manufacturers, human resource development (i.e. education and training) "overshadowed capital investment, information technologies, and improving organizational structures and processes as the top concern of Indiana manufacturers. In fact, 85 percent of the survey respondents believe 
the biggest obstacle to sustained growth in Indiana manufacturing is the shortage of qualified workers." 8,12

Given the concerns of our national innovation infrastructure and Indiana's challenges in education and training, the purpose of this paper is to explore the idea of technology leadership education and to propose an initiative focused on integrating technology leadership into technical education programs in the state of Indiana. Providing an educational pathway for technically trained students to advance and develop leadership/innovation strategies will be one of the essential building blocks of educating the next generation in Indiana. There is a demand for leaders and innovators to emerge in high-technology fields versus those that simply "manage" the tools. Thus this paper outlines a proposed educational pathway from high school and Associate's degrees through a Certificate and Bachelor's degree so that students can pair technical skills with leadership competence.

\section{Literature on Technology Leadership}

The literature exploring technology leadership is not extensive as it is within each of the domains separately (leadership and technology). However, the connection between the two is apparent. For example, this connection is explored within the organizational development literature. Orlikowski ${ }^{13}$ stated that technology "has always been a central variable in organizational theory" (p. 398) with two prominent views of technology apparent: (a) as hardware (artifacts) and (b) as the tasks, techniques, and knowledge used in productive activities. Orlikowski argued that there are three streams of research on technology in organizational settings: (a) technology as an objective, external force, (b) the human interaction with technology, and (c) a "soft" determinism where human actors and organizational contexts mediate technology impacts. Liker, Haddad, and Karlin ${ }^{10}$ described four paradigms of explaining technology in organizations consisting of: (a) technological determinism, (b) management of technology, (c) political interests, and (d) intepretivist. The technological determinism paradigm sees technology as a causal variable where organizations must adapt to technology. The reverse of this view, where technology and organizations can be planned and integrated, is the management of technology paradigm. With the political interests paradigm, static, predictable interests influence outcomes. The interpretivist paradigm sees technology as socially constructed, where technology implementation is an emergent process.

In terms of leadership specifically, researchers have discussed the impact of technology on leadership, largely focusing on information technology ${ }^{17}$ and virtual collaboration. ${ }^{9,}{ }^{16}$ For example, e-leadership has been offered as a theoretical model for leading virtually through technology. Avolio ${ }^{2}$ conducted a review of e-leadership research and offered a framework based on Adaptive Structuration Theory. This framework builds upon the socio-technical systems approach and the belief that social and technical system alignment is crucial for organizational effectiveness. Leadership within this framework is a source of structures that influences action, including the appropriation of technology.

Despite the literature exploring technology within organizations and its impact on leadership, there is little exploring technology leadership as a combined concept. Even though not explicitly leadership, technology management literature provides some pertinent insights. Technology 
management "has become a cross-disciplinary academic field of inquiry, built from the foundations of strategic management theory, systems theory, organizational behavior, sociology, economics, finance, political science, and industrial relations" (p. 582) ${ }^{10}$. For example, Cetindamar, Phaal, and Probert ${ }^{4}$ offered a framework based on dynamic capabilities theory to capture the evolving nature of technology and the need for flexible capabilities. In addition, numerous technology management programs have emerged across college campuses in the United States. Liker, Haddad, and Karlin ${ }^{10}$ argued that the underlying theory of such programs is that "the right technology design, in combination with the right implementation process, leads to the desired outcomes, provided the predictable process is followed with care" (p. 582).

In order to address the gap in the literature on technology leadership, Daugherty, Mentzer, Lybrook, and Little-Wiles engaged in work to define technology leadership by examining the philosophical and research-based literature ${ }^{7}$ and by reviewing academic programs that integrate technology and leadership or management ${ }^{6}$. The definition that they offer for a technology leader is: someone who enables others to understand and operate within the processes used to modify the natural world to create the designed world contributing to effectiveness and success. This definition describes those individuals who have the responsibility to lead others engaged in creating, designing, and managing technology. Leaders must possess a broad base of technological knowledge; its processes, products, and implications, as well as the leadership skills necessary to be able to influence change and motivate others. Using the definition as a spring board, Little-Wiles, Hackney, and Daugherty, explored whether the definition had merit in "the real world," by conducting a small-scale, exploratory study using semi-structured interviews to identify characteristics of technology leadership across several contexts (as diverse as health care to high technology manufacturing companies). ${ }^{11}$ Their results conclude that technology leadership is a distinct role mainly at higher organizational levels and that there are important defining characteristics including curiosity, technical knowledge, communication skills, and leading change.

Building on the definition offered by Daugherty et al. ${ }^{7}$, Bowen, Bertoline, Athinarayanan, Cox, Burbank, Buskirk, and Kucukonal conducted observations and interviews with individuals at 16 academic and industry organizations in multiple countries to gather data on the development and status of technology leadership education ${ }^{3}$. The findings of this study include a bifurcation in programmatic approaches and conceptualizations of technology leadership between established and relatively younger higher educational programs. In addition, industry-academic partnerships and the role of leadership and management scientific training in higher education were identified as critical considerations. Bowen, et al. added that "the consistent awareness of the need to place global technology leadership within a comprehensive system/framework rather than as an isolated degree program is a significant step forward in beginning the process of advancing understanding of the whole construct" (p. 170). ${ }^{3}$

\section{Technology Leadership Pathways Program}

Technology-rich organizations need people who can pair technical knowledge, skills, and abilities with an ability to lead people. A gap exists between what organizations need from employees in the way of technical competence and what organizations need in the way of

leadership competency. ${ }^{1,23}$ High-ranking managers in technology-rich organizations have 
indicated a gap between those technologically trained and the demands of leadership positions. ${ }^{11}$ Several organizations invest in developing leaders, seeing it as a source of competitive advantage. However, others are unable and the gap has broadened. Historically, organizations have focused on hiring employees with either a strong technical competence or a strong leadership competence; however, the $21^{\text {st }}$ century technology leader will need both.

Thus, we are presenting the following pathway as a means to fill the "leadership gap" in tomorrow's workforce (see Figure 1).

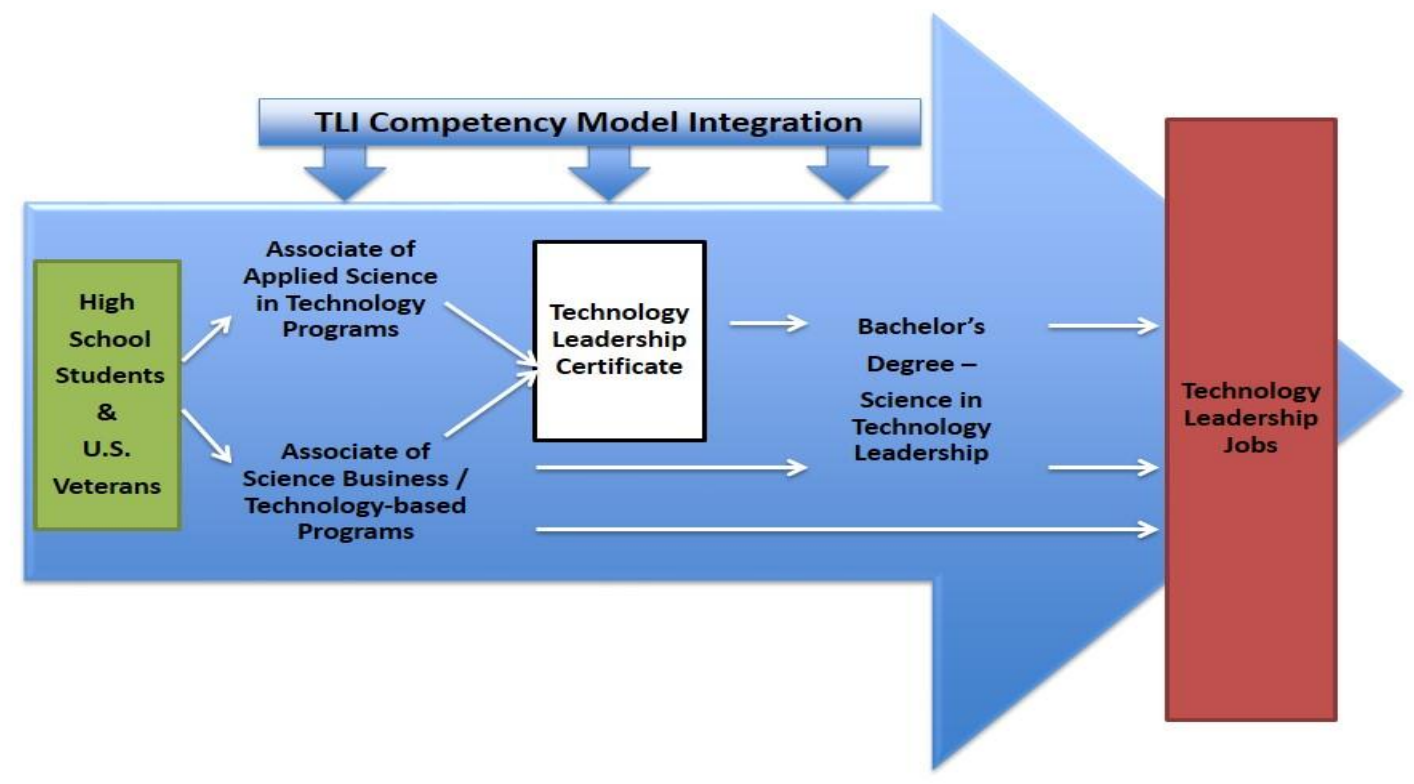

Figure 1. Technology Leadership \& Innovation (TLI) Pathway.

The Technology Leadership Pathway program will provide an educational pathway to leadership competencies for Indiana's next generation of students. The proposed pathway will be a collaborative effort between a statewide community college and a department at a research university. A Technology Leadership competency model will be developed and will be incorporated within the curriculum of select statewide community college Associates of Science (AS) / Applied Associates of Science (AAS) degrees and an appropriate Bachelor of Science (BS) degree program at the research university. AAS degrees at the statewide community college are two year degrees designed to prepare the student for a vocational position in the workforce. These degree programs are designed toward a specific position and the sixty credit hours necessary does not include exposure to technology leadership or leadership competencies. This pathway opportunity will be especially valuable to these students in preparing them for advanced leadership positions.

The program is designed to allow the student to enter the pathway at any point; however, part of the initiative will focus on attracting high school students and U.S. military veterans. Once in the pathway students can earn a technical AS / AAS degree from the statewide community college and a certificate in Technology Leadership from the research university. The combination of 
these two awards (a technical associate's degree and a leadership certificate) will aid students in obtaining employment in technology-rich organizations. Students with exceptional merit may choose to stay on the pathway and earn a BS degree from the research university in Technology Leadership.

One of the reasons this proposed program targets high school students is because a recent report examining Indiana workforce trends found that high school students who entered college soon after graduating high school are more likely to complete their degree rather than waiting to return later in life. ${ }^{5}$ In addition, the research literature on successful strategies for retaining STEM students is to provide support mechanisms that enable students to stay connected and motivated throughout their educational programs. ${ }^{19} 22$ This approach is inherent to the pathways model that encourages retention.

Additionally this program will also be focused upon reaching veterans. Approximately 3.4 percent of Indiana community college students are identified as military or veteran students with approximately 2.3 percent of the total student population benefiting from VA educational benefits. The project team will distribute materials to the Indiana Department of Veterans Affairs, which includes logistics careers as part of the new Veterans Retraining Assistance Programs (VRAP), approved in 2012. ${ }^{22}$ The VRAP program focuses on training veterans through educational benefits for programs in high demand careers. In collaboration with the VRAP veterans will be able to take a pathway from military skills to the Certificate through AS / AAS degrees to BS degrees at the university partner.

\section{Industrial Leadership Board and Technology Leadership Competency Model}

The 21st Century leader needs both technical knowledge and leadership skills. One of the strengths of this pathway program is its close connection to what industry wants and needs. Thus it is necessary to form a shared Industrial Leadership Board (ILB) between the statewide community college and the research university to provide current industry insight into the skills and occupations of technology leadership. Members of the ILB should include persons from various technology-rich organizations throughout the region that have a need to hire technology leadership employees. Information about industry needs will be collected from these members in the form of interviews and focus groups in order to leverage their expertise and understanding of leadership competence within their respective technology fields. The timely feedback from the ILB will continually inform the identification and development of leadership competencies and technology leadership. ${ }^{11}$

In addition to the ILB, an important component informing the educational outcomes of the pathway will be a Technology Leadership competency model. The developing competency model looks at core competencies of leadership that are essential for people who work in technology-rich organizations. As suggested in the literature review, leadership is a broad construct with a significant literature base. The competency model will help to identify those competencies that are most critical for technology students and then will be used to develop/modify curriculum at the community college and university partner.

\section{Technology Leadership Certificate and Curriculum}


Utilizing the Technology Leadership competency model, we will develop the content for a Technology Leadership certificate. Course content of the certificate will reflect those essential competencies, allowing all students who complete to develop a technology leadership skill set. Further, we will use the working competency model to develop and refine courses in the AS / AAS programs at the statewide community college and the university program, with a focus on students demonstrating their technology leadership skills.

Collaborative work between the statewide community college and the research university will develop curriculum in an effort to align with the growing needs of technology leadership in industry as specified in the Technology Leadership competency model. The need for educational programs in technology is evident with the emphasis on technician skills. Stronger leadership is also a mainstream business requirement that is needed in every business. Through selection of applicable statewide community college degree programs and investigation of present degree requirements between these programs, the gaps between the bachelor degree program and the AS / AAS degree programs can be identified.

In addition, the creation of a Technology Leadership certificate will address the job growth as identified in the Occupation Report. ${ }^{15}$ Jobs growth in technology and technology related supervisory/leadership positions is expected to grow about 10\% between 2013 and 2022. With input from the Industrial Leadership Board, the statewide community college and research university will design a 15-credit certificate to equip AS / AAS students with necessary additional skills and knowledge to qualify for these positions. This certificate will provide access for students with an AAS degree to directly enter the workforce with enhanced leadership skills or to continue towards an AS degree with the option of a subsequent BS. The goal will be to create seamless transitions for the students at every stage of their post-secondary education by ensuring integration of coursework and appropriate coverage of course prerequisites.

\section{Long-Term Sustainability of the Pathway}

There are several best practices that will be used to develop a sustainable pathway program. Cross-institutional student peer mentoring activities, cross-institutional coaching, students that are further along their academic pathway mentoring newer students, face-to-face networking, industry-student engagement, and peer student social gatherings may all serve to create a network for supporting students and encouraging persistence along the pathway. These types of practices that occur outside the classroom can be as engaging as activities in the classroom. ${ }^{24}$ An important component of these practices will be to provide opportunities to interact with industry partners via our Industrial Leadership Board. For example, through the academic semester, students in the technology leadership pathway will interact through informal, social activities, such as industry tours, as well as formal opportunities such as internships and team projects.

A Virtual Learning Community (VLC) will be an important component of the pathway program. A virtual learning community is a learning community, which includes several types of digital communication. These include electronic networks, chat rooms, tele- and videoconferences, and online communities. There are advantages to the variety offered by non-face-to-face interaction in learning communities, including benefiting the learning process by ensuring clearer 
communication and encouraging participation from all students. ${ }^{19}$ Students involved in learning communities persist at a higher rate than comparable students in a traditional curriculum. ${ }^{21}$ The VLC for the Technology Leadership Pathway will be dedicated to increasing students' persistence toward the Technology Leadership certificate or degree and provide collaboration along the pathway. The VLC's mission will be to bring students from 2- and 4-year institutions together for the purpose of engaging in interaction and providing support. If the VLC is successful, a face-to-face learning community may also be established for those who would prefer an alternate to virtual communication.

\section{Evaluation}

A multi-method evaluation of the Technology Leadership pathway program will be used to collect data about the program's success and to help refine and improve it along the way. Data from multiple stakeholders will be collected and used to answer the following questions:

- Are the marketing and recruitment plans a good fit for the target audiences (formative)?

- In what ways does the student support system reflect best practices (formative and process)?

- In what ways do the competency model and curricular materials fill the gaps identified through the analysis (formative and process)?

- To what extent is the project meeting its targets for students who enter and persist in the pathway and certificate program(process)?; and

- To what extent do participation in the VLC result in enhanced pathway entry and/or persistence (summative)?

Formative data will be gathered from high school and community college students to guide the development of the materials created. Early in the project, focus groups with each target audience will be used to review the virtual marketing plan, mock-ups of hard copy recruitment materials, and the plans for interacting with students. Feedback will be collected and used to guide the project as it develops.

Several components of the process and summative evaluation will be developed. A value creation map will be constructed to document pathway trajectory presented in Figure 1. In this way, the value creation map will documents how each of the pieces interact with one another to inform the creation and implementation of the pathway.

Later evaluation will expand to include the larger groups of faculty and other stakeholders involved in the project. The questions asked of these groups will be modeled after the SpecificValue Creation Matrix ${ }^{20}$ that captures five types of values: (a) immediate (the value of the community's activities and interactions), (b) potential (knowledge capital that is produced but not necessarily used in the immediate situation), (c) applied (adapting and applying knowledge in different contexts), (d) realized (application that leads to improvement in performance), and (f) reframing (reconsideration/redefining of perspectives, processes and/or structures; pp. 19-21).

\section{Conclusions}


Leadership has been identified as being crucially important for today's global society. And as Pennington, Weeks, Weeks, Barbuto, and Langone ${ }^{14}$ argued, there is a need across the country for faculty to teach leadership within specific disciplines. This includes technology. Technology leaders must possess technological expertise, as well as leadership skills such as the ability to influence and motivate others. The Technology Leadership Pathway model we described is designed to do this; enable students to develop technological expertise and build leadership skills.

There are admittedly many challenges to implementation of this pathway program. As it is currently still in development there will undoubtedly be roadblocks. These challenges can be loosely divided into procedural changes and those challenges that are more academic in nature.

Every new venture has procedural hurdles. At the foundation of this proposal is a collaboration between two large institutions of higher education. While both have successfully collaborated on past projects, there is nonetheless a potential for significant procedural hurdles. Each institution has its own policies, politics, and organizational demands that may influence the implementation of this initiative.

In regards to challenges of a more academic nature, this project relies on developing a technology leadership competency model. The data that is initially collected for this model may indicate something different than what is in the existing literature. For instance, the technology leadership competency model might be too complex to pedagogically incorporate into a single degree program or certificate. Similarly, there may be issues with the specific technology that a student chooses to pair with technology leadership. What if there are, for instance, different leadership competencies associated with different types of technology (i.e. leadership skills needed for computer graphics technology versus leadership skills needed for mechanical engineering)? However, all of these examples are many of the same challenges that any new venture will encounter. Through testing, trial, and adaption they will be overcome.

The Technology Leadership Pathway program proposed here is designed for two specific institutions and the state of Indiana. However, there is the potential for broader applicability of this model. If it can be implemented and shown to be successful in Indiana then it could be adapted for other states and other institutions of higher learning. This program could then be used as a roadmap for higher education institutions in other states to integrate technical competency and leadership skills within their students and course curriculum.

\section{References}

1. Antonakis, J., Cianciolo, A.T., \& Sternberg, R.J. (2004). The Nature of Leadership, Thousand Oaks, CA: Sage.

2. Avolio, B. J. (2000). E-leadership: Implications for theory, research, and practice. The Leadership Quarterly, 11(4), 615-668.

3. Bowen, E. E., Bertoline, G. R., Athinarayanan, R., Cox, R. F., Burbank, K. A., Buskirk, D. R., \& Kucukonal, H. (2013). Global technology leadership: A case for innovative education praxis. Procedia - Social and Behavioral Sciences, 75, 163-171. 
4. Cetindamar, D., Phaal, R., \& Probert, D. (2009). Understanding technology management as a dynamic capability: A framework for technology management activities. Technovation, 29(4), 237-246.

5. Conover, J., Rogers, C., Slaper, T., Foston, A., \& Justis, R. (2011). The Importance of Being Educated: Wage Benefits for Indiana's Adult Students, Indiana Business Research Center, Kelley School of Business, Indiana University.

6. Daugherty, J.L., Mentzer, N. J., \& Lybrook, D.O. (2010). Perspectives on technology leadership. In Technological Learning and Thinking: Culture, Design, Sustainability, Human Ingenuity International Conference Proceedings. Vancouver, Canada.

7. Daugherty, J.L., N.J. Mentzer, D.O. Lybrook, \& Little-Wiles, J. (2013) Philosophical perspectives on technology leadership. In Wang, S., \& Hartsell, T. (Eds.). Technology integration and foundations for effective technology leadership. IGI Global, 42-56.

8. Frohlich, M., Brown, S., \& Jones, S.L. (2012). Shortage of Qualified Workers is Indiana's

9. Huang, R., Kahai, S., \& Jestice, R. (2010). The contingent effects of leadership on team collaboration in virtual teams. Computers in Human Behavior, 26(5), 1098-1110.

10. Liker, J. K., Haddad, C. J., \& Karlin, J. (1999). Perspectives on technology and work organization. Annual Review of Sociology, 25, 575-596.

11. Little-Wiles, J., Hackney, K., \& Daugherty, J. L. (2012). Identifying the technology leader across contexts: A discussion of common characteristics. In International Leadership Association Annual Global Conference Proceedings, Denver, CO.

12. Manufacturing's Big Obstacle. Inside Indiana Business. Retrieved from: http://www.insideindianabusiness.com/contributors.asp?ID=2368

13. Orlikowski, W. J. (1992). The duality of technology: Rethinking the concept of technology in organizations. Organization Science, 3(3), 398-427.

14. Pennington Weeks, P., Weeks, W.G., Barbuto, J.E., \& Langone, C.A. (2009). The challenge of developing faculty to teach leadership as a secondary discipline. Journal of Leadership Education, 8(1), 207-215.

15. Schwab, K. (Ed.). 2011. The Global Competitiveness Report, 2011-2012, World Economic Forum.

16. Sutanto, J., Tan, C-H., Battistini, B., \& Phang, C. W. (2011). Emergent leadership in virtual collaboration settings: A social network analysis approach. Long Range Planning, 44(5-6), 421-439.

17. Taleghani, M. \& Mousavian, S. J. (2011). Determining the relationship between information technology and leadership style (case study: Navy Research Institute of Bandar Anzali in Northern Iran). Journal of Information Engineering and Applications. 1,(6), 5-15.

18. U.S. Census Bureau - Indiana Quick Facts. Retrieved from: http://quickfacts.census.gov/qfd/states/18000.html2012

19. Watkins, J. \& Mazur, E. (2013). Retaining students in science, technology, engineering, and mathematics (STEM) majors. Journal of College Science Teaching, 42(5), 36-41.

20. Wenger, E., Trayner, B., \& de Latt, M. (2011). Promoting and assessing value creation in communities and networks: A conceptual framework. Rapport 18, Ruud de Moor Centrum, Open University of the Netherlands.

21. Wessner C.W., \& Wolff, A.W. (Ed.). (2012). Rising to the Challenge: U.S. Innovation Policy for Global Economy. National Academies - Committee on Comparative National Innovation Policies: Best Practice for the 21st Century. Board on Science, Technology, and Economic Policy, Policy and Global Affairs, National Research Council.

22. Wilson, Z.S., Holmes, L., deGravelles, K., Sylvain, M.R., Batiste, L., Johnson, M., McGuire, S.Y., Pang, S.S., \& Warner, I.M. (2011). Hierarchical mentoring: A transformative strategy for improving diversity and retention in undergraduate STEM disciplines. Journal of Science Education and Technology, 21(1), 148-156.

23. Yukl, G. (2013). Leadership in Organizations (8th ed.), Boston, MA: Pearson.

24. Zhao, C.M. \& Kuh, G. (2004). Adding Value: Learning Communities and Student Engagement. Research in Higher Education, 45(2). 